\title{
Spatial Patterns and Climate Drivers of Malaria in Three Border Areas of Brazil, Venezuela and Guyana, 2016-2018
}

Kinley Wangdi ( $\sim$ kinley.wangdi@anu.edu.au )

ANU https://orcid.org/0000-0002-8857-2665

Erica Wetzler

World Vision US

Horace Cox

Vector Borne Diseases Unit, Ministry of Health, Guyana

Paola Marchesini

Department of Surveillance and Vector-Borne Diseases, Malaria Techinical Group, Ministry of Health

\section{Leopoldo Villegas}

Global Development One, Maryland

\section{Sara Canavati}

World Vision US

\section{Research Article}

Keywords: Malaria, climatic variables, hotspot, spatial analysis, Brazil, Venezuela, Guyana, transmission, imported malaria, cross-border malaria

Posted Date: December 29th, 2021

DOI: https://doi.org/10.21203/rs.3.rs-1185425/v1

License: (c) (1) This work is licensed under a Creative Commons Attribution 4.0 International License.

Read Full License 


\section{Abstract}

\section{Introduction}

In 2020, $77 \%$ of malaria cases in the Americas were concentrated in Venezuela, Brazil, and Colombia. These countries are characterized by a heterogeneous malaria landscape and malaria hotspots. Furthermore, the political unrest in Venezuela has led to significant cross-border population movement. Hence, the aim of this study was to describe spatial patterns and identify significant climatic drivers of malaria transmission along the Venezuela-Brazil-Guyana border, focusing on Bolivar state, Venezuela and Roraima state, Brazil.

\section{Methods}

Malaria case data, stratified by species from 2016-2018, were obtained from the Brazilian Malaria Epidemiology Surveillance Information System, the Guyana Vector Borne Diseases Program, the Venezuelan Ministry of Health, and civil society organizations. Spatial autocorrelation in malaria incidence was explored using Getis-Ord (Gi*) statistics. A Poisson regression model was developed with a conditional autoregressive prior structure and posterior parameters were estimated using the Bayesian Markov chain Monte Carlo simulation with Gibbs sampling. Climatic covariates were precipitation and minimum and maximum temperature.

\section{Results}

There were 685,498 malaria cases during the study period. Plasmodium vivax was the predominant species $(71.7 \%, 490,861)$. Malaria hotspots were located in eight municipalities along the Venezuela and Guyana international borders with Brazil. Plasmodium falciparum decreased by $1.6 \%$ ( $95 \%$ credible interval $[\mathrm{Crl}] 1.5 \%, 2.3 \%)$ and $9.6 \%(95 \% \mathrm{Crl} 1.5 \%, 25.2 \%)$ per $1 \mathrm{~cm}$ increase in six-month lagged precipitation and each $1^{\circ} \mathrm{C}$ increase of minimum temperature without lag. Each $1^{\circ} \mathrm{C}$ increase of onemonth lagged maximum temperature increased $P$. falciparum by $6.6 \%(95 \% \mathrm{Crl} 4.8 \%, 21.7 \%)$. P. vivax cases decreased by $1.0 \%(95 \% \mathrm{Crl} 1.0 \%, 1.1 \%)$ and $7.0 \%$ (95\% $\mathrm{Crl} 6.5 \%, 7.5 \%)$ for each $1 \mathrm{~cm}$ increase of precipitation lagged at six-months and $1{ }^{\circ} \mathrm{C}$ increase in minimum temperature lagged at six-months. There was no significant residual spatial clustering after accounting for climatic covariates.

\section{Conclusion}

Malaria hotspots were located along the Venezuela and Guyana international border with Roraima state, Brazil. In addition to population movement, climatic variables are important drivers of malaria transmission in these areas.

\section{Introduction}

The WHO World Malaria Report 2021 showed that there were an estimated 241 million malaria cases and 627,000 malaria deaths worldwide in 2020. This represents about 14 million more cases in 2020 
compared to 2019 , and 69,000 more deaths. Approximately two-thirds of these additional deaths $(47,000)$ were linked to disruptions in the provision of malaria prevention, diagnosis and treatment during the pandemic [1].

In the WHO Region of the Americas, malaria cases and case incidence reduced by $58 \%$ (from 1.5 million to 0.65 million) and $67 \%$ (from 14.1 to 4.6 cases per 1000 population at risk) between 2000 and 2020 [1]. Over the same period, there was reduction in both malaria deaths and mortality rate reduced by $56 \%$ (from 909 to 409 ) and $66 \%$ (from 0.8 to 0.3 deaths per 100,000 population at risk), respectively [1]. Progress in this region suffered in recent years because of a major increase in malaria in the Bolivarian Republic of Venezuela, which had about 35500 cases in 2000, rising to over 467000 by 2019 [1]. In 2020 , cases reduced to 232,000, which is half of 2019 cases [1]. This was attributed to restrictions on movement during the COVID-19 pandemic and fuel shortage leading to reduced mining activities. As a result, occupational exposure risk to malaria vectors was significantly decreased [1].

So far, in the region, Argentina, Paraguay and El Salvador have eliminated malaria [1-3]. While, Belize reported zero malaria cases for the second consecutive year in 2020 [1]. In addition, French Guiana, Guatemala, Honduras and Peru all met the global technical strategy 2020 malaria morbidity milestone of a reduction of at least $40 \%$ in case incidence [1]. However, this progress has stalled in some places in recent years, with the rise in cases mainly due to the major increase in malaria in Venezuela $[2,4]$. The country has been under a severe economic, political, and social crisis and all national institutions have been affected. The collapse of the Venezuelan health system has resulted in the deterioration of all facets of malaria prevention and control $[5,6]$. Stock-outs of antimalarial drugs have been common, exacerbating malaria transmission [5].

Furthermore, the political unrest in Venezuela has led to significant cross-border population movement [7]. More than 5.2 million people have left the country since 2015, and there has been a marked influx of Venezuelan nationals arriving in neighboring countries [7]. Malaria transmission in the WHO Region of the Americas is heterogeneous [8,9] and four countries accounted for $77 \%$ of malaria cases in 20202 [1]. It has been documented that several factors are responsible for the continued transmission of malaria such as climatic, ecological and human factors, further characterized by spatial clustering of cases in transmission hotspots $[10,11]$. If malaria control interventions in hotspot areas are not sustained, these hotspots can serve as the source of infection to neighbouring regions and to countries that have eliminated malaria or where transmission has been interrupted [12, 13]. Delineation of malaria hotspots can help to identify the underlying reasons for higher incidence of malaria in particular areas [14], which can serve to target interventions where they are most needed, likely having a greater impact than uniform resource allocation [11].

Spatial analysis and modelling enable the prediction of disease patterns and determination of ecological associations between disease risk and the environment $[11,15,16]$. It is well known that geospatial methods can be used to link disease data to vector habitats, vector presence, abundance and density; quantify spatial diffusion; and characterize spatial and temporal patterns of disease [17-24]. This paper 
aimed to describe spatial patterns and climatic drivers of malaria from 2016 to 2018 in Brazil (Roraima state), Venezuela (Bolivar state) and four regions of Guyana, all located in the Guyana Shield.

\section{Methods}

\section{Study area and data}

The study area included three border areas: Roraima state in Brazil, Bolivar state in Venezuela and four regions of Guyana (Fig. 1). Roraima and Bolivar are divided into 15 and 11 municipalities, respectively. Individual-level, de-identified datasets were obtained from national surveillance systems and additional sources: the Brazilian Malaria Epidemiology Surveillance Information System (SIVEP-Malaria), the Guyana Vector Borne Diseases Program, the Venezuelan Ministry of Health, and civil society organizations in Venezuela. Individual-level data were extracted on age, sex and malaria species. The populations of the municipalities were obtained from national census projections in each country $[25,26]$. Monthly precipitation, and minimum and maximum temperature at 30 second intervals from January 2016 to December 2018 were obtained from the WorldClim database [27]. Municipality polygon was used to extract the mean climatic variables using Zonal statistics in ArcMap 10.5.1 (ESRI Inc., Redlands, CA, USA). An electronic map of municipalities in shapefile format was obtained from the DIVA-GIS database (https://www.diva-gis.org/).

\section{Hotspot analysis}

The presence and nature of spatial autocorrelation that suggest malaria case clustering by place of notification were assessed by the Getis-Ord statistic $\left(\mathrm{Gi}^{\star}\right)[28,29]$. The local Getis-Ord statistic $\left(\mathrm{Gi}^{*}\right)$ was used to identify the intensity and stability of hotspot/cold spot clusters $[29,30]$. The Gi* statistic compares the local malaria mean rate (i.e., the rate of malaria for a target location and its neighbors) to the global malaria mean rate (the rates of all municipalities). The $\mathrm{Gi}^{*}$ statistic compares the $\mathrm{z}$-score and p-value for each municipality with global malaria means. Location with a statistically significant and larger z-score will have a more intense clustering of high values (hotspots), where it is unlikely that the spatial clustering of high values is the result of a random spatial process; and locations with statistically significant and smaller z-scores will have more intense clustering of low values (cold spots) [29]. ArcMap 10.5.1 software (ESRI, Redlands, CA) was used for hotspot analysis and creating maps.

\section{Crude standardized morbidity ratios}

An initial descriptive analysis of malaria incidence was conducted. Crude standardized morbidity ratios (SMRs) for each municipality were calculated using the following formula:

$$
Y_{i}=\frac{O_{i}}{E_{i}}
$$


where $Y$ is the overall SMR in municipality $i, O$ is the total number of observed malaria cases in the municipality and $E$ is the expected number of malaria cases in the municipality across the study period. The expected number was calculated by multiplying the national incidence by the average population for each municipality over the study period.

\section{Independent variable selection}

A preliminary Poisson regression was undertaken to select climatic covariates for each species. Climatic variables of precipitation, minimum and maximum temperature without a lag, and with one to 12-month lag times were entered into univariate models. Minimum temperature without lag, one-month lagged maximum temperature and six-month lagged precipitation had the lowest values of the Akaike's information criterion (AIC) for P. falciparum (Additional file 1: Table S1). One-month maximum temperature and six-month lagged precipitation and minimum temperature were selected for $P$. vivax with the lowest AIC (Additional file 1: Table S2). The co-linearity of the climatic variables was tested using variance inflation factors (VIF) (Additional file 1: Table S3, S4).

\section{Spatio-temporal model}

Poisson regression models were developed in the Bayesian statistical software WinBUGS version 1.4 (Medical Research Council, Cambridge, UK and Imperial College London, UK) for $P$. falciparum and $P$. vivax. Alternative models were tested for each species including models with climatic variables such as precipitation, minimum and maximum temperature as explanatory variables, and spatially structured and unstructured random effects. The best model was selected based on the lowest deviation information criterion (DIC) for each species. Three models were developed: Model I consisted of climatic explorative variables and unstructured random effects; Model II contained the same explorative variables as Model I and spatially structured random effects. Model III contained both structured and unstructured random effects and climatic explorative variables. Model III was the most comprehensive model, which had as an outcome the observed counts of malaria, $Y$, for $i^{\text {th }}$ municipality $(i=1 \ldots 30)$ in the $j^{\text {th }}$ month (January 2016December 2018) was structured as follows:

$Y_{i j k l} \otimes$ Poisson $\left(\mu_{i j k k}\right)$

$\log \left(\mu_{i j k l}\right)=\log \left(\mathrm{E}_{i j k l}\right)+\theta_{i j k l}$

$\theta_{i j k l}=a+\beta_{1} \times$ trend $+\beta_{2} \times$ Precipitation $_{i j}+\beta_{3} \times \operatorname{Tempmin}_{i j}+\beta_{4} \times \operatorname{Tempmax}_{i j}+\mathrm{u}_{i}+\mathrm{s}_{i}$

where $E$ is the expected number of cases (acting as an offset to control for population size) and $\theta$ is the mean log relative risk (RR); $a$ is the intercept, and $\beta_{1}, \beta_{2}, \beta_{3}$, and $\beta_{4}$ the coefficients for trend, precipitation, minimum and maximum temperature, respectively; $u_{i}$ is the unstructured random effect (assumed to have a mean of zero and variance $\sigma_{u}{ }^{2}$ ) and $s_{i}$ is the spatially structured random effect (assumed to have a mean of zero and variance $\sigma_{\mathrm{s}}{ }^{2}$ ). 
A conditional autoregressive (CAR) prior structure was used to model the spatially structured random effect. An adjacency weights matrix was used to calculate the spatial relationships between the municipalities. A weight of 1 was assigned if two municipalities shared a border and 0 if they did not. A flat prior distribution was specified for the intercept, whereas a normal prior distribution was specified for the coefficients. The priors for the precision of unstructured and spatially structured random effects were specified using non-informative gamma distributions with shape and scale parameters. Models were also developed without the structured and unstructured random effects to assess whether inclusion of these components improved model fit.

An initial burn-in of 10,000 iterations was run, and these iterations were discarded. Subsequent blocks of 20,000 iterations were run and examined for convergence. Convergence was assessed by visual inspection of posterior density and history plots, and occurred at approximately 100,000 iterations for each model. Ten thousand values from the posterior distributions of each model parameter were stored and summarized for the analysis (posterior mean and 95\% credible intervals [Crl]).

In all analyses, an a-level of 0.05 was adopted to indicate statistical significance (as indicated by $95 \% \mathrm{Crl}$ for RR that excluded 1). ArcMap 10.5.1 software (ESRI, Redlands, CA) was used to generate maps of the posterior means of the unstructured and structured random effects and the spatiotemporal random effects obtained from the three models.

\section{Results}

\section{Descriptive analysis}

There were a total of 684,498 malaria cases recorded during the study period, and $88.3 \%(604,306)$ of these cases were reported from Bolivar state, Venezuela. Compared to 2016, malaria cases across the study areas increased from $25.5 \%(174,635)$ to $37.5 \%(256,482)$ and $37.0 \%(253,381)$ cases in 2017 and 2018 , respectively. More than two-thirds of cases were in males $(67.5 \%, 461,912)$. The predominant species was $P$. vivax $(71.7 \%, 490,861)$ followed by $P$. falciparum $(22.4 \%, 153,512)$. However, mixed infections with $P$. vivax and $P$. falciparum consisted of $4.6 \%(8,008), 5.7 \%(14,492)$ and $6.9 \%(17,381)$ in 2016, 2017 and 2018, respectively (Table 1). Mean precipitation, and minimum and maximum temperature were $150.5 \mathrm{~mm}$ (range $1.1-413.6 \mathrm{~mm}$ ), $21.9^{\circ} \mathrm{C}$ (range $16.9^{\circ} \mathrm{C}-24.6^{\circ} \mathrm{C}$ ) and $31.1^{\circ} \mathrm{C}$ (range $26.8^{\circ} \mathrm{C}-35.2^{\circ} \mathrm{C}$ ), respectively (Additional file 1: Table S5). The $P$. falciparum SMR varied from 0.0 to 14.94 during the study period, and Pacaraima municipality in Roraima state and Sifontes municipality in Bolivar state reporting the highest SMR with ranges increasing each year: 2016 (SMR 6.20-14.94), 2017 (SMR 4.45-14.28) and 2018 (SMR 6.1-17.04) (Fig. 2). The P. vivax SMR varied from 0.0 to 18.78 during the study period with Sifontes municipality again reporting the highest SMR: 2016 (SMR 6.68-18.78), 2017 (SMR 8.42-18.78) and 2018 (SMR 6.07-18.18) (Fig. 3). 
Table 1

Demographic characteristics of malaria from 2016 to 2018.

\begin{tabular}{|cllll|}
\hline Characteristics & Year & & \multicolumn{2}{c}{ p-value* } \\
\cline { 2 - 4 } & $\mathbf{2 0 1 6}$ & $\mathbf{2 0 1 7}$ & $\mathbf{2 0 1 8}$ & \\
\hline Country & Number (\%) & Number (\%) & Number (\%) & \\
\hline Roraima, Brazil & $8,969(5.1)$ & $14,082(5.5)$ & $23,369(9.2)$ & $<0.001$ \\
\hline Guyana & $8,355(4.8)$ & $11,139(4.3)$ & $14,278(5.6)$ & \\
\hline Bolivar, Venezuela & $157,311(90.1)$ & $23,1261(90.2)$ & $215,734(85.1)$ & \\
\hline Total & $174,635(25.5)$ & $256,482(37.5)$ & $253,381(37.0)$ & \\
\hline Sex & & & & $<0.001$ \\
\hline Female & $53,839(30.8)$ & $83,136(31.4)$ & $85,611(33.8)$ & \\
\hline Male & $120,796(69.2)$ & $173,346(76.6)$ & $167,770(66.2)$ & \\
\hline Age category (years) & & & & $<0.001$ \\
\hline 0-18 & $41,123(23.7)$ & $62,715(24.5)$ & $61,618(24.4)$ & \\
\hline 19-30 & $63,891(36.8)$ & $89,782(56.0)$ & $89,926(35.6)$ & \\
\hline 31-40 & $34,107(19.6)$ & $50,397(19.7)$ & $50,311(19.9)$ & \\
\hline 40+ & $34,597(19.9)$ & $52,797(20.7)$ & $50,914(20.1) \mathrm{s}$ & \\
\hline Species & & & & \\
\hline P. falciparum & $37,217(21.3)$ & $53,138(20.7)$ & $63,157(24.9)$ & $<0.001$ \\
\hline P. vivax & $129,354(74.1)$ & $188,755(73.6)$ & $172,752(68.2)$ & \\
\hline P. malariae & $11(0.0)$ & $13(0.0)$ & $15(0.0)$ & \\
\hline Mixed & $8,008(4.6)$ & $14,492(5.7)$ & $17,381(6.9)$ & \\
\hline p-value significant at $<0.05$ & & & \\
\hline & & & & \\
\hline
\end{tabular}

\section{Spatial autocorrelation}

Applying the Getis-Ord G* statistic hotspot analysis to $P$. falciparum and $P$. vivax incidence in each municipality revealed statistically significant $(p<0.01)$ hotspots in eight border municipalities of Venezuela and Guyana: Piar, Padre Pedro Chien, Roscio, El Callao and Sifontes in Bolivar state and Barina-Waini and Cuyuni-Mazaruni in Guyana (Fig. 4 and 5).

\section{Spatio-temporal model}


Model I, containing the unstructured random effect, had the best fit and was the most parsimonious of all the models, examined for both $P$. falciparum and $P$. vivax, as indicated by the lowest DIC (Table 2). For $P$. falciparum, monthly malaria cases increased by $2.1 \%$ (95\% Crl: $1.9,2.113 \%)$ per month during the study period. One cm increase in six-month lagged precipitation and each $1^{\circ} \mathrm{C}$ increase of minimum temperature was associated with $1.6 \%$ (95\% Crl 1.5\%, 2.3\%) and 9.6\% (95\% Crl 1.5\%, 25.2\%) decrease of $P$. falciparum, respectively. Each $1^{\circ} \mathrm{C}$ increase of one-month lagged maximum temperature increased $P$. falciparum by $6.6 \%(95 \% \mathrm{Crl} 4.8 \%, 21.7 \%)$. Monthly $P$. vivax increased by $1.0 \%$ (95\% $\mathrm{Crl} 0.9 \%, 1.0 \%)$ during the study period. P. vivax cases decreased by $1.0 \%(95 \% \mathrm{Crl} 1.0 \%, 1.1 \%)$ for each $\mathrm{cm}$ increase of precipitation lagged at six-months and $7.0 \%(95 \% \mathrm{Crl} 6.5 \%, 7.5 \%)$ for $1^{\circ} \mathrm{C}$ increase in minimum temperature lagged at six-months (Table 2). There is no evidence of spatial clustering after accounting for model covariates (Fig. 6). 
Table 2

Regression coefficients, RRs and 95\% Crl from Bayesian spatial and non-spatial models for Plasmodium falciparum and Plasmodium vivax from 2016 to 2018.

\section{Plasmodium falciparum \\ Plasmodium vivax \\ $\operatorname{RR}(95 \% \mathrm{Crl})$ \\ $\operatorname{RR}(95 \% \mathrm{Crl})$}

\section{Model I}

Monthly trend

$1.021(1.019,1.021)$

$1.010(1.009,1.010)$

Precipitation (10mm)

$0.984(0.977,0.985)$

$0.990(0.989,0.990)$

Temp Min (degree Celsius) $\quad 0.904(0.748,0.928)$

$0.930(0.925,0.935)$

Temp Max (degree Celsius) $1.065(1.048,1.217)$

$1.001(0.997,1.005)$

Heterogeneity ${ }^{\star}$

$\begin{array}{lll}\text { Structured (trend) } & 9.96 \times 10^{1}\left(9.87 \times 10^{-2}, 5.05 \times 10^{2}\right) & 1.01 \times 10^{2}\left(9.91 \times 10^{-2}, 5.03 \times 10^{2}\right) \\ \text { Unstructured } & 1.94 \times 10^{-5}\left(1.10 \times 10^{-5}, 3.03 \times 10^{-5}\right) & 1.85 \times 10^{-5}\left(1.05 \times 10^{-5}, 2.97 \times 10^{-5}\right) \\ \mathrm{DIC}^{\ddagger} & 50209.5 & 124085\end{array}$

Model II

Monthly trend

$1.021(1.014,1.021)$

$1.010(1.009,1.010)$

Precipitation (10mm)

$0.984(1.016,0.985)$

$0.990(0.989,0.990)$

Temp Min (degree Celsius)

$0.916(0.608,0.929)$

$0.930(0.925,0.935)$

Temp Max (degree Celsius)

$1.056(1.115,1.064)$

$1.001(0.997,1.005)$

Heterogeneity ${ }^{\star}$

\begin{tabular}{lll} 
Structured (trend) & $0.93 \times 10^{1}\left(9.82 \times 10^{-2}, 5.04 \times 10^{2}\right)$ & $9.97 \times 10^{1}\left(9.88 \times 10^{-2}, 5.02 \times 10^{2}\right)$ \\
\hline Structured (spatial) & $8.59 \times 10^{-2}\left(4.80 \times 10^{-2}, 1.35 \times 10^{-1}\right)$ & $1.26 \times 10^{-1}\left(6.95 \times 10^{-2}, 1.98 \times 10^{-1}\right)$ \\
\hline DIC & 50663.1 & 124127
\end{tabular}

Model III

Monthly trend

$1.021(1.019,1.021)$

$1.010(1.009,1.010)$

Precipitation (10mm)

$0.998(0.998,0.999)$

$0.990(0.989,0.990)$

Temp Min (degree Celsius)

$0.904(0.748,0.928)$

$0.930(0.925,0.935)$

Crl- credible interval; DIC- deviation information criteria; RR- relative risk

${ }^{*}$ Co-efficient; ${ }^{\text {tbest fit model }}$ 
Plasmodium falciparum

RR (95\% Crl)

Temp Max (degree Celsius) $1.065(1.048,1.217)$
Plasmodium vivax

$\mathrm{RR}(95 \% \mathrm{Crl})$

$1.001(0.997,1.005)$

Heterogeneity ${ }^{*}$

Structured (trend)

$1.01 \times 10^{2}\left(9.78 \times 10^{-2}, 5.08 \times 10^{2}\right)$

$1.00 \times 10^{2}\left(9.47 \times 10^{-2}, 3.03 \times 10^{2}\right)$

Unstructured

$4.69 \times 10^{-4}\left(1.93 \times 10^{-4}, 1.93 \times 10^{-3}\right)$

$4.11 \times 10^{-4}\left(2.12 \times 10^{-4}, 6.88 \times 10^{-4}\right)$

Structured (spatial)

$3.04 \times 10^{-4}\left(8.31 \times 10^{-5}, 7.61 \times 10^{-4}\right)$

$1.43 \times 10^{-4}\left(7.25 \times 10^{-5}, 2.37 \times 10^{-4}\right)$

DIC

50933.2

124167

Crl- credible interval; DIC- deviation information criteria; RR- relative risk

${ }^{\star}$ Co-efficient; ${ }^{\ddagger}$ best fit model

\section{Discussion}

This study aimed to describe spatial patterns and climatic drivers of malaria in the border states of Brazil, Venezuela and Guyana using national malaria surveillance data from 2016 to 2018 . The great majority of malaria cases were reported from Bolivar state in Venezuela: 157,311 (90.1\%), 23,1261 (90.2\%), and 215,734 (85.1\%) from 2016 to 2018 , respectively. The most commonly reported malaria species was $P$. vivax $(172,752,71.7 \%)$. Hotspots of both $P$. falciparum and $P$. vivax were located in the border municipalities of Venezuela and Guyana. $P$. falciparum transmission was positively associated with precipitation lagged at six-months and maximum temperature lagged at one-month and negatively associated with minimum temperature. Whereas $P$. vivax was negatively associated with precipitation and minimum temperature lagged at six-months.

Since 1990, the majority of malaria cases in Venezuela have come from Bolivar state: $>60 \%$ (1992-1995) and 88\% (2000-2014) [7, 31-33], with most cases clustering in Sifontes municipality (Bolivar State) [7]. Additionally, in Sifontes municipality, gold mining has been associated with a high incidence of malaria, with miners accounting for up to $80 \%$ of cases $[8,9,31,34]$. In contrast to progress made in neighboring countries and in the Americas, the political and economic crisis in Venezuela has thwarted malaria control efforts. Malaria cases have increased significantly in recent years: from 35,500 cases in 2000 to over 467,000 cases in 2019 [2].

Our study showed that malaria hotspots were consistently found in municipalities along the VenezuelaGuyana border with Brazil, including Sifontes municipality, and in municipalities adjacent to Sifontes municipality, including Piar, Padre Pedro Chien, Roscio, and El Callao in Bolivar state. Sifontes municipality was recently identified as the most important cluster of malaria transmission in the Americas [7]. This highlights the issue of cross-border malaria, which can impact malaria control efforts 
$[35,36]$. A plausible solution can be cross-country collaboration to improve surveillance and finding ways to provide early diagnosis and treatment for border populations, which are usually more mobile and difficult to track. Higher cases in these regions have also been related to occupation, especially gold mining [37]. Gold mining drives increased population movement to mining sites, usually young males [8]. Our findings confirmed this. Males made up two-thirds of cases and more than half of malaria cases were in the 19-40 year age group (Table 1). Furthermore, poor living conditions and working outdoors during late at night or early in the morning also could expose miners to increased mosquito bites.

Plasmodium vivax was the predominant species in this study and is also the primary species in the Americas $[34,38]$. Relapse of $P$. vivax is associated with the release of dormant hypnozoites from the liver. Challenges to correct diagnosis include lack of sensitive diagnostic tools. Rapid Diagnostic Tests (RDTs), which are widely used in the region and globally, are unable to diagnose dormant hypnozoites in the liver or in pregnant women. Secondly, adherence to $P$. vivax treatment is a main challenge, which includes a three-day course of chloroquine and 7 or 14 days of primaquine $[39,40]$. Hence, continued $P$. vivax transmission in other parts of world has been attributed to lack of adherence to treatment $[41,42]$. Since cross-border populations are hard to follow up, we propose implementation of community-based adherence support, which has been used for HIV and TB and has significantly improved treatment [4345]. Treatment follow up can be done through a friend or family member who is travelling with the patient or someone who is part of the patient's community such as a community member, a support group, and/or a religious leader.

Climatic variables of precipitation and temperature are also associated with the transmission of malaria in this study. The transmission of the malaria parasite and mosquito survival are affected by temperature $[46,47]$. At temperatures of $22^{\circ} \mathrm{C}$, it takes less than three weeks to complete the life cycle of malaria parasite development in the mosquito vector [48]. The biting rate and gonotrophic processes are also temperature dependent $[49,50]$. Other studies have reported rainfall as an important driver of malaria transmission [51, 52]. The main vectors responsible for malaria transmission in the Americas, including Anopheles darlingi and An. Albimanus, are also affected by climate [53-56].

There are some limitations to this study. First, the main limitation is the lack of completeness and representativeness of surveillance data. Second, populations of municipalities were projected, which may have resulted in over or under estimation. Third, unmeasured risk modifiers including socio-economic development, living standards, occupation, treatment, localized behavioral patterns, population mobility, and bed net use and residual indoor insecticide coverage were unaccounted for in this study.

\section{Conclusion}

Plasmodium falciparum and $P$. vivax transmission was negatively associated with increased precipitation and minimum temperature, and positively associated with maximum temperature. Hotspots of both $P$. falciparum and $P$. vivax were isolated in eight municipalities along the Venezuela and Guyana international border with Brazil. Targeted distribution of resources, including intensified interventions in 
hotspot municipalities, will be required for effective control of local malaria transmission. Furthermore, cross-border surveillance needs to be strengthened and ongoing identification of hotspots is needed to stay on track with malaria elimination targets.

\section{Abbreviations}

AIC Akaike's information criterion

CAR conditional autoregressive

Crl credible interval

DIC deviation information criterion

RR relative risk

SIVEP-Malaria Brazilian Malaria Epidemiology Surveillance Information System

SMRs standardized morbidity ratios

VIF variance inflation factors

WHO World Health Organization

\section{Declarations}

\section{Ethics approval and consent to participate}

The National Center of Bioethics in Venezuela (CENABI) approved the research protocol and the National Survey Ethics Council (CONEP) considered that ethical clearance for the use of this secondary data in Brazil was not necessary. Not applicable. Human participants were not involved in the study. This research uses secondary data and is not subject to ethics approval.

\section{Consent for publication}

Not applicable.

\section{Availability of data and materials}

The study dataset can be made available only upon the approval by researchers and organizations involved.

\section{Competing interests}

The authors declare that they have no competing interests. 


\section{Funding}

This study was supported by World Vision US, Global Development One, USA, and Asociacion Civil Impacto Social (ASOCIS), Venezuela.

\section{Authors' contributions}

All authors were involved in the conceptualization and design of the study. EW, HC, PM, LV and SC were involved in data acquisition. KW and $\mathrm{EW}$ undertook the data cleaning and statistical analysis. KW drafted the manuscript. EW, HC, PM, LV and SC provided critical revision of the manuscript. All authors read and approved the final manuscript.

\section{Acknowledgements}

Authors would like to thank the Ministries of Health of Brazil, Guyana and Venezuela for sharing the data, and all of the health workers in Roraima and Bolivar for their contributions to collecting and reporting the data. We would also like to thank Jorge Moreno (Centro de Investigación de Campo Francesco Vitanza, Tumeremo, Bolívar, Venezuela) and Maria Villegas (Global Development One, Silver Spring, Maryland, USA) who supported data acquisition and entry for the data from Bolivar state.

\section{References}

1. WHO. World Malaria Report 2021. (Organization WH ed. Geneva, Switzerland2021.

2. WHO. World Malaria Report 2020. Geneva: World Health Organization; 2020.

3. Burton RA, Chévez JER, Sauerbrey M, Guinovart C, Hartley A, Kirkwood G, et al. Factors Associated with the Rapid and Durable Decline in Malaria Incidence in El Salvador, 1980-2017. Am J Trop Med Hyg. 2018;99:33-42.

4. Grillet ME, Hernández-Villena JV, Llewellyn MS, Paniz-Mondolfi AE, Tami A, Vincenti-Gonzalez MF, et al. Venezuela's humanitarian crisis, resurgence of vector-borne diseases, and implications for spillover in the region. Lancet Infect Dis. 2019;19:e149-e61.

5. Rodríguez-Morales AJ, Paniz-Mondolfi AE. Venezuela's failure in malaria control. Lancet. 2014;384:663-4.

6. Oletta JF, Orihuela RA, Pulido P, Walter C. Venezuela: violence, human rights, and health-care realities. Lancet. 2014; 383:1967.

7. Grillet ME, Moreno JE, Hernández-Villena JV, Vincenti-González MF, Noya O, Tami A, et al. Malaria in Southern Venezuela: The hottest hotspot in Latin America. PLoS Negl Trop Dis. 2021;15:e0008211.

8. Recht J, Siqueira AM, Monteiro WM, Herrera SM, Herrera S, Lacerda MVG. Malaria in Brazil, Colombia, Peru and Venezuela: current challenges in malaria control and elimination. Malar J. 2017;16:273.

9. Recht J, Siqueira AM, Monteiro WM, Herrera SM, Herrera S, Lacerda MVG. Malaria Transmission in South America- Present Status and Prospects for Elimination. London: IntechOpen; 2018. 
10. Wangdi K, Xu Z, Suwannatrai AT, Kurscheid J, Lal L, Namgay R, et al. A spatio-temporal analysis to identify the drivers of malaria transmission in Bhutan. Sci Rep. 2020;10:7060.

11. Clements ACA, Reid HL, Kelly GC, Hay SI. Further shrinking the malaria map: how can geospatial science help to achieve malaria elimination? Lancet Infect Dis. 2013;13:709-18.

12. Wangdi K, Gatton ML, Kelly GC, Banwell C, Dev V, Clements AC. Malaria elimination in India and regional implications. Lancet Infect Dis. 2016;16:e214-24.

13. Wangdi K, Singhasivanon P, Silawan T, Lawpoolsri S, White NJ, Kaewkungwal J. Development of temporal modelling for forecasting and prediction of malaria infections using time-series and ARIMAX analyses: a case study in endemic districts of Bhutan. Malar J. 2010; 9:251.

14. Sweeney AW. The Application of GIS in Malaria Control Programs,. 10th Colloquium of the Spatial Information Research Centre,University of Otago, New Zealand,. 16-19 November, 1998.

15. Richards TB, Croner CM, Rushton G, Brown CK, Fowler L. Geographic information systems and public health: mapping the future. Public Health Rep. 1999;114:359-73.

16. Malone JB, Bergquist R, Martins M, Luvall JC. Use of Geospatial Surveillance and Response Systems for Vector-Borne Diseases in the Elimination Phase. Trop Med Infect Dis. 2019; 4.

17. Wangdi K, Banwell C, Gatton ML, Kelly GC, Namgay R, Clements AC. Development and evaluation of a spatial decision support system for malaria elimination in Bhutan. Malar J. 2016;15::180.

18. Wangdi K, Canavati SE, Ngo TD, Nguyen TM, Tran LK, Kelly GC, et al. Spatial and Temporal Patterns of Malaria in Phu Yen Province, Vietnam, from 2005 to 2016. Am J Trop Med Hyg. 2020;103:154048.

19. Wangdi K, Clements AC. Spatial and temporal patterns of diarrhoea in Bhutan 2003-2013. BMC Infect Dis. 2017;17:507.

20. Wangdi K, Clements ACA, Du T, Nery SV. Spatial and temporal patterns of dengue infections in TimorLeste, 2005-2013. Parasit Vectors. 2018;11:9.

21. Kelly GC, Hale E, Donald W, Batarii W, Bugoro H, Nausien J, et al. A high-resolution geospatial surveillance-response system for malaria elimination in Solomon Islands and Vanuatu. Malar J. 2013;12::108.

22. Kelly GC, Seng CM, Donald W, Taleo G, Nausien J, Batarii W, et al. A spatial decision support system for guiding focal indoor residual spraying interventions in a malaria elimination zone. Geospatial health. 2011;6:21-31.

23. Kelly GC, Tanner M, Vallely A, Clements A. Malaria elimination: moving forward with spatial decision support systems. Trends Parasitol. 2012;28:297-304.

24. Kalluri S, Gilruth P, Rogers D, Szczur M. Surveillance of arthropod vector-borne infectious diseases using remote sensing techniques: a review. PLoS Pathog. 2007;3:1361-71.

25. IBGE Censo. 2010 [https://censo2010.ibge.gov.br/sinopse/].

26. INE. Venezuela Census 2011. 2018.

27. Historical climate data [https://www.worldclim.org/data/worldclim21.html]. 
28. Anselin L, Getis A. Spatial statistical analysis and geographic information systems. Annals of Regional Science. 1992;26:19-33.

29. Ord JK, Getis A. Local spatial autocorrelation statistics: distributional issues and an application. Geographical analysis. 1995;27:286-306.

30. Zulu LC, Kalipeni E, Johannes E. Analyzing spatial clustering and the spatiotemporal nature and trends of HIV/AIDS prevalence using GIS: the case of Malawi, 1994-2010. BMC Infect Dis. 2014;14::285.

31. Moreno JE, Rubio-Palis Y, Martínez ÁR, Acevedo P. Evolución espacial y temporal de la malaria en el municipio Sifontes del estado Bolívar, Venezuela. 1980-2013\%J Boletín de Malariología y Salud Ambiental. 2014; 54:236-49.

32. Grillet ME, El Souki M, Laguna F, León JR. The periodicity of Plasmodium vivax and Plasmodium falciparum in Venezuela. Acta Trop. 2014;129:52-60.

33. Gabaldón-Figueira JC, Chaccour C, Moreno J, Villegas M, Villegas L. The malaria burden of Amerindian groups of three Venezuelan states: a descriptive study based on programmatic data. Malar J. 2021;20:285.

34. Douine M, Lambert $Y$, Musset $L$, Hiwat $H$, Blume LR, Marchesini P, et al. Malaria in Gold Miners in the Guianas and the Amazon: Current Knowledge and Challenges. Current Tropical Medicine Reports. 2020;7:37-47.

35. Wangdi K, Gatton ML, Kelly GC, Clements AC. Cross-border malaria: a major obstacle for malaria elimination. Adv Parasitol. 2015;89:79-107.

36. Wangdi K, Pasaribu AP, Clements ACA. Addressing hard-to-reach populations for achieving malaria elimination in the Asia Pacific Malaria Elimination Network countries. Asia Pac Policy Stud. 2021; n/a:1-13.

37. Arisco NJ, Peterka C, Castro MC. Cross-border malaria in Northern Brazil. Malar J. 2021;20:135.

38. de Oliveira EC, dos Santos ES, Zeilhofer P, Souza-Santos R, Atanaka-Santos M. Geographic information systems and logistic regression for high-resolution malaria risk mapping in a rural settlement of the southern Brazilian Amazon. Malar J. 2013;12::420.

39. Wangchuk S, Drukpa T, Penjor K, Peldon T, Dorjey Y, Dorji K, et al. Where chloroquine still works: the genetic make-up and susceptibility of Plasmodium vivax to chloroquine plus primaquine in Bhutan. Malar J. 2016;15:277.

40. Thriemer K, Bobogare A, Ley B, Gudo CS, Alam MS, Anstey NM, et al. Quantifying primaquine effectiveness and improving adherence: a round table discussion of the APMEN Vivax Working Group. Malar J. 2018;17:241.

41. Grietens KP, Soto V, Erhart A, Ribera JM, Toomer E, Tenorio A, et al. Adherence to 7-day primaquine treatment for the radical cure of P. vivax in the Peruvian Amazon. Am J Trop Med Hyg. 2010;82:1017-23.

42. Pereira EA, Ishikawa EA, Fontes CJ. Adherence to Plasmodium vivax malaria treatment in the Brazilian Amazon Region. Malar J. 2011;10:355. 
43. Rogers JH, Jabateh L, Beste J, Wagenaar BH, McBain R, Palazuelos D, et al. Impact of communitybased adherence support on treatment outcomes for tuberculosis, leprosy and HIV/AIDS-infected individuals in post-Ebola Liberia. Glob Health Action. 2018;11:1522150.

44. Grimwood A, Fatti G, Mothibi E, Malahlela M, Shea J, Eley B. Community adherence support improves programme retention in children on antiretroviral treatment: a multicentre cohort study in South Africa. J Int AIDS Soc. 2012;15:17381.

45. Community Adherence Clubs. Breaking Down Barriers to Treatment in Namibia https://www.cdc.gov/globalhivtb/who-we-are/success-stories/success-storypages/communityadherenceclubs.html.

46. Brooker S, Clarke S, Njagi JK, Polack S, Mugo B, Estambale B, et al. Spatial clustering of malaria and associated risk factors during an epidemic in a highland area of western Kenya. Trop Med Int Health. 2004;9:757-66.

47. Noden $\mathrm{BH}, \mathrm{Kent} \mathrm{MD}$, Beier JC. The impact of variations in temperature on early Plasmodium falciparum development in Anopheles stephensi. Parasitology. 1995;111(Pt 5):539-45.

48. Teklehaimanot HD, Lipsitch M, Teklehaimanot A, Schwartz J. Weather-based prediction of Plasmodium falciparum malaria in epidemic-prone regions of Ethiopia I. Patterns of lagged weather effects reflect biological mechanisms. Malar J. 2004;3::41.

49. Tompkins AM, Ermert V. A regional-scale, high resolution dynamical malaria model that accounts for population density, climate and surface hydrology. Malar J. 2013;12::65.

50. Paaijmans KP, Blanford S, Bell AS, Blanford JI, Read AF, Thomas MB. Influence of climate on malaria transmission depends on daily temperature variation. Proc Natl Acad Sci U S A. 2010;107:15135-9.

51. Craig MH, Snow RW, le Sueur D. A climate-based distribution model of malaria transmission in subSaharan Africa. Parasitol Today. 1999;15:105-11.

52. Thomson MC, Mason SJ, Phindela T, Connor SJ. Use of rainfall and sea surface temperature monitoring for malaria early warning in Botswana. Am J Trop Med Hyg. 2005;73:214-21.

53. Zimmerman RH. Ecology of malaria vectors in the Americas and future direction. Mem Inst Oswaldo Cruz. 1992;87(Suppl 3):371-83.

54. Laporta GZ, Linton YM, Wilkerson RC, Bergo ES, Nagaki SS, Sant'Ana DC, et al. Malaria vectors in South America: current and future scenarios. Parasit Vectors. 2015;8:426.

55. Batista EP, Costa EF, Silva AA. Anopheles darlingi (Diptera: Culicidae) displays increased attractiveness to infected individuals with Plasmodium vivax gametocytes. Parasit Vectors. 2014;7:251.

56. Rios-Velásquez CM, Martins-Campos KM, Simões RC, Izzo T, dos Santos EV, Pessoa FA, et al. Experimental Plasmodium vivax infection of key Anopheles species from the Brazilian Amazon. Malar J. 2013;12::460.

\section{Figures}




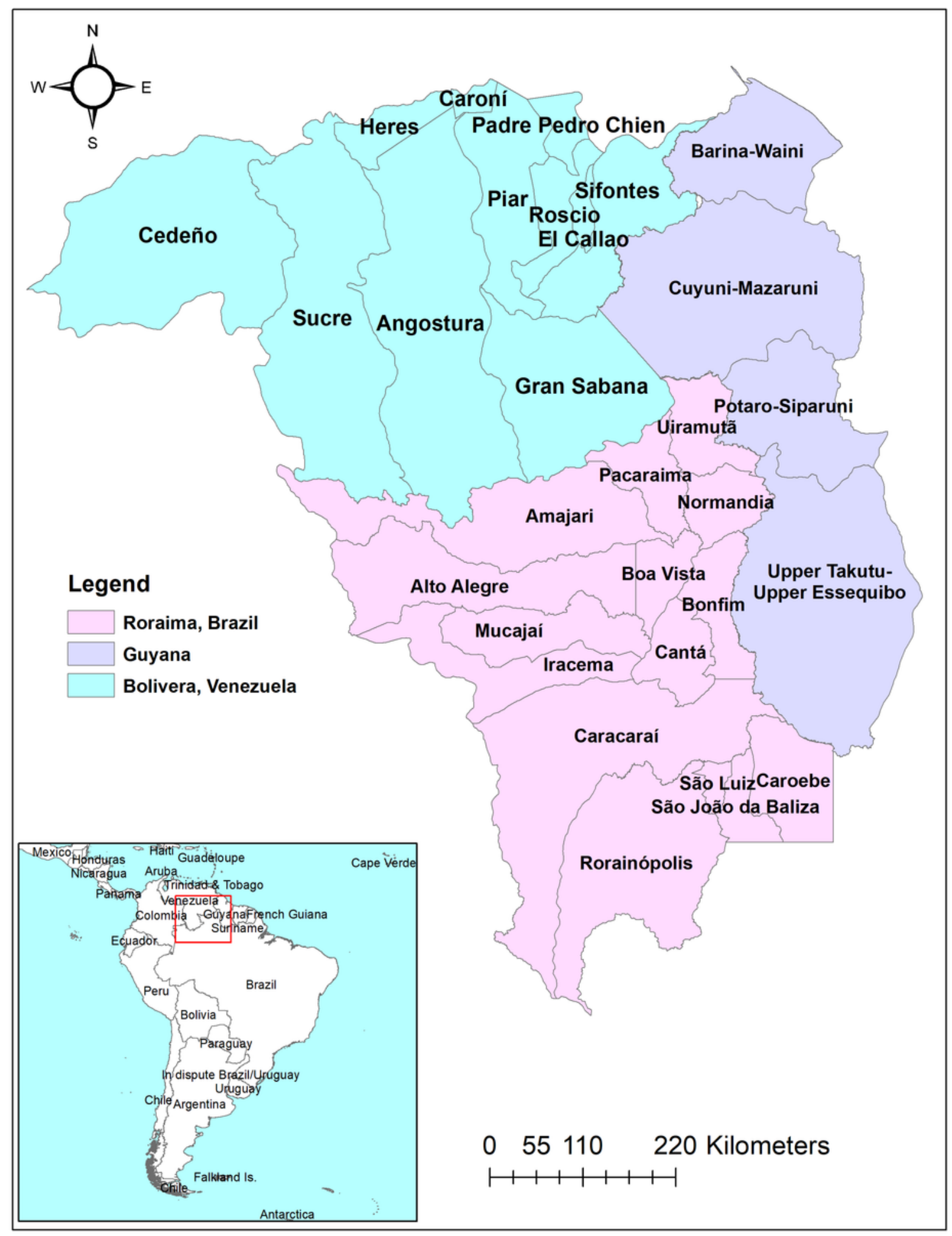

Figure 1

Map of the study areas. 


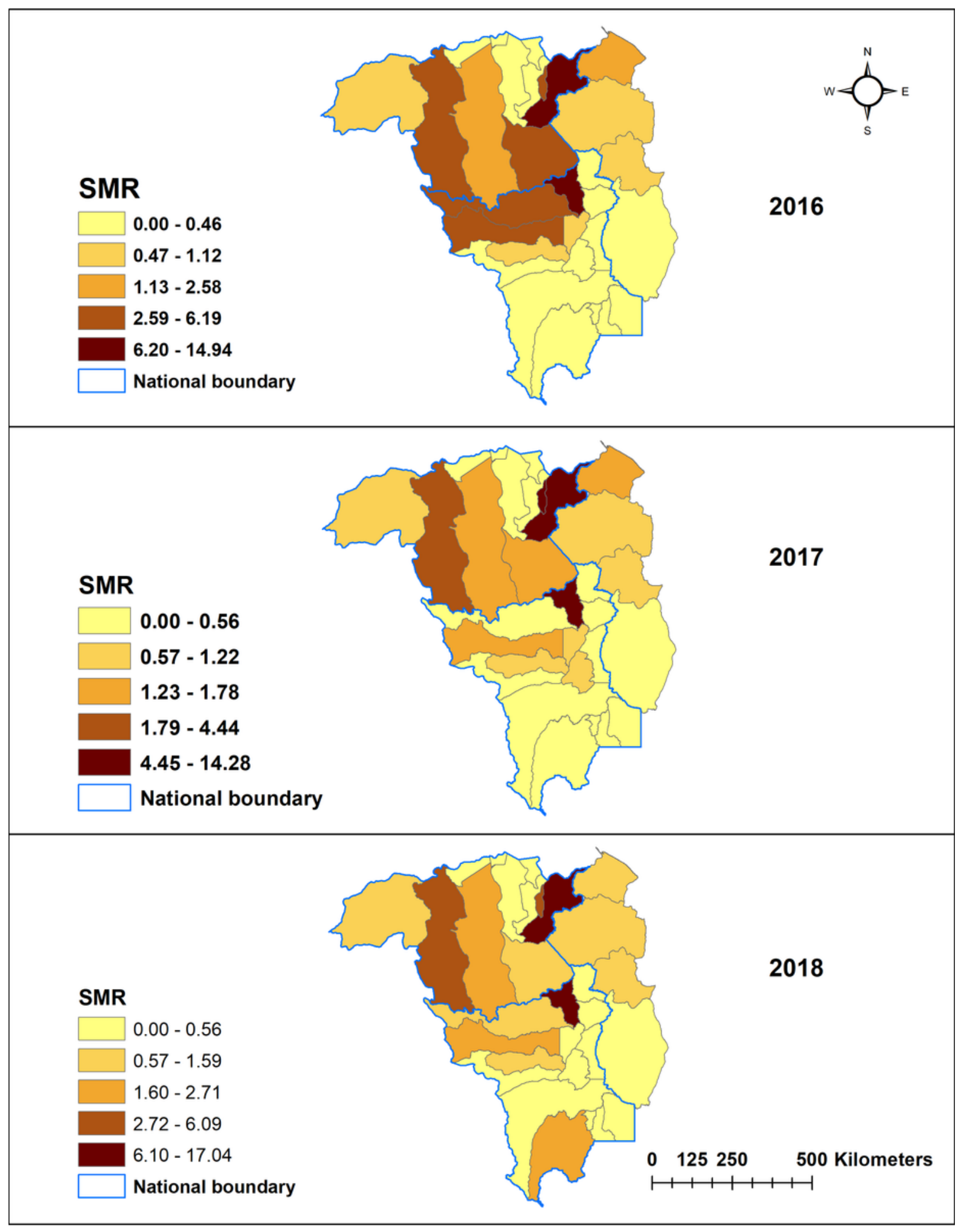

Figure 2

Raw standardized morbidity ratios of Plasmodium falciparum, 2016-2018.

Figure 3 
Raw standardized morbidity ratios of Plasmodium vivax, 2016-2018.

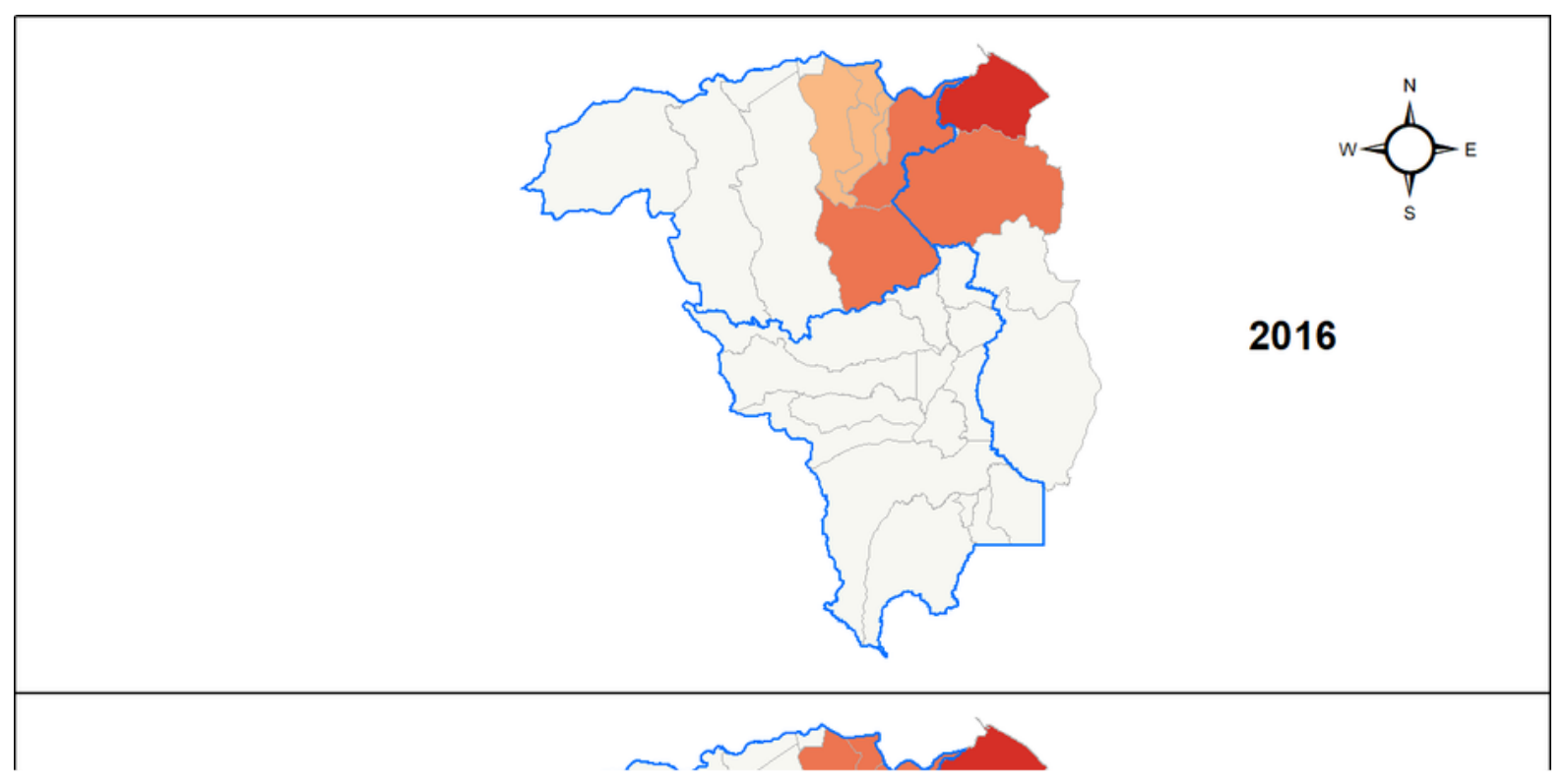

Figure 4

Hot spots (Getis-Ord Gi*) of Plasmodium falciparum. 


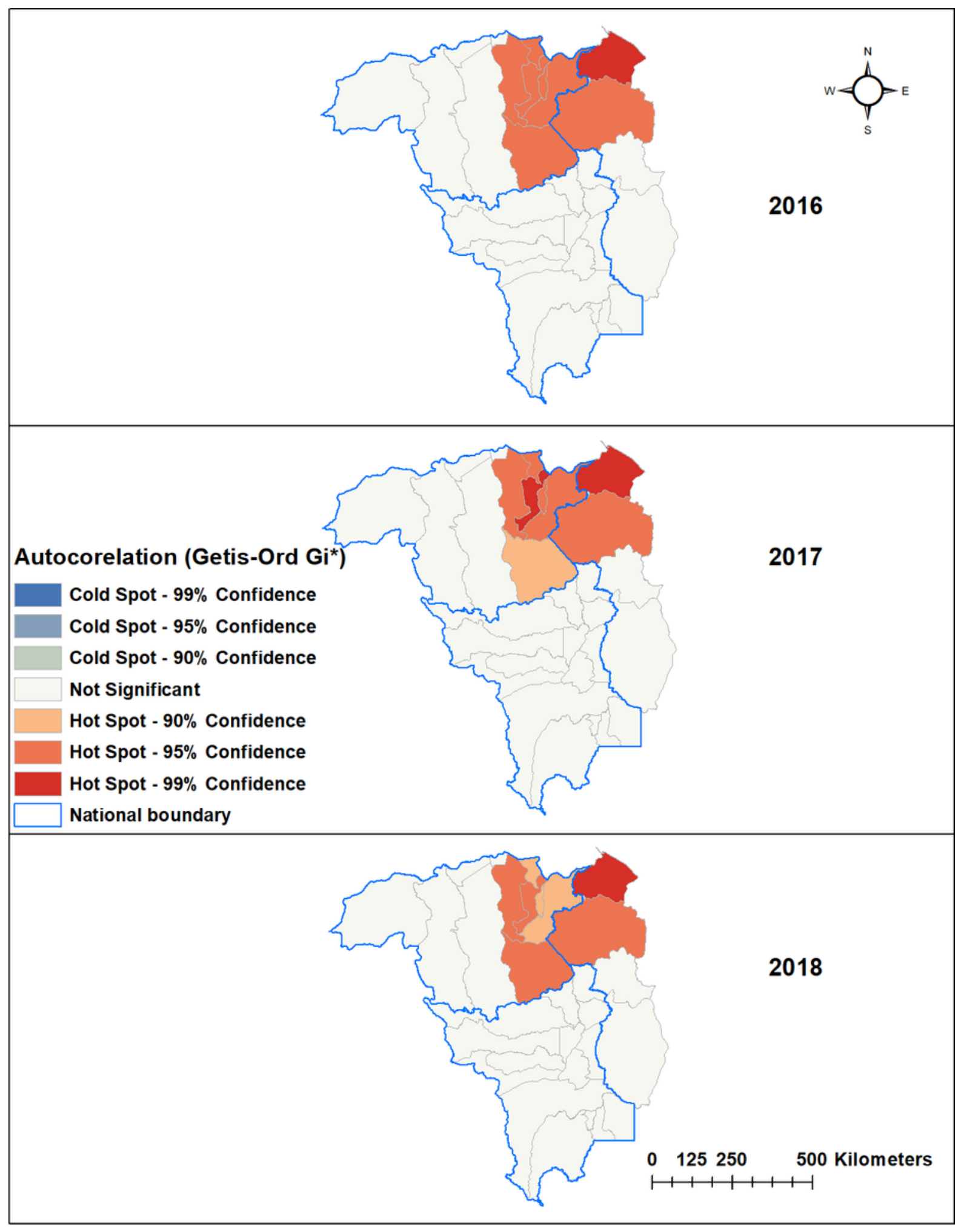

Figure 5

Hot spots (Getis-Ord Gi*) of Plasmodium vivax. 


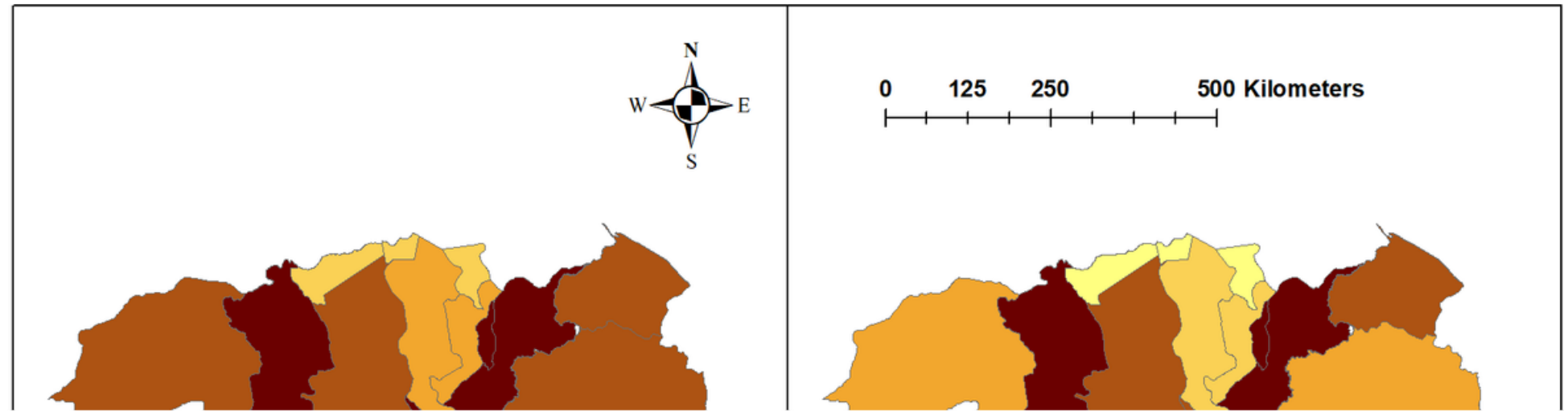

Figure 6

Spatial distribution of the posterior means of unstructured random effects for (a) Plasmodium falciparum and (b) Plasmodium vivax in Model I.

\section{Supplementary Files}

This is a list of supplementary files associated with this preprint. Click to download.

- Supplementarymaterials.docx 